\title{
The influence of temperature on the deformation of columns in the nave of the Saint Vitus Cathedral at the Prague Castle
}

Received (in revised form): 5th January, 2007

\begin{abstract}
Pavel Beran
graduated from the Faculty of Civil Engineering, Czech Technical University (CTU) in Prague in 2005. The theme of his diploma project was 'Saint Vitus Cathedral - Temperature Loading'. He is currently studying for a PhD at the Department of Mechanics, Faculty of Civil Engineering, specialising in 'Statics of Historical Structures'.
\end{abstract}

\section{Jiři Máca}

is a reader (associate professor) at the Faculty of Civil Engineering, CTU in Prague. He previously received his Master's degree at the same University in 1981 and a PhD at the Klokner Institute, CTU in 1987. He specialises in dynamics, statics of structures, and numerical and experimental analysis of structures.

Correspondence: Pavel Beran, Faculty of Civil Engineering, Czech Technical University in Prague, Thákurova 7, 16629 , Praha 6 - Dejvice, Czech Republic; Tel: (+420) 22435 4498; Fax: (+420) 22431 0775; E-mail: pavel.beran@fsv.cvut.cz

\section{Abstract}

The Saint Vitus Cathedral is a dominant part of the Prague Castle, which falls within the UNESCO World Heritage reserve. For future preservation of the Cathedral, it is important to determine any potential displacement of its loadbearing structure that can be done by geodetic measurement. It was necessary to take account of the differences between the theoretical deformations and the geodetic measurement for a correct interpretation and detection of the reasons for the measured displacements. These analyses revealed that temperature changes were the main cause of the measured deformations.

Journal of Building Appraisal (2007) 2, 313-322. doi:10.1057/palgrave.jba.2950056

\section{Keywords:}

numerical model, temperature extensibility, geodetic measurement

\section{INTRODUCTION}

The Prague Castle, which was founded about 1,000 years ago, ranks among the major historical landmarks of the Czech nation and is one of the greatest buildings in the capital city. The major component of the Castle is the Saint Vitus Cathedral (Figure 1), which was first built in the 14th century. Geodetic monitoring of such a historically important building can help detect early signs of structural degradation, and can therefore facilitate repair or ideally help to identify how and why the building is degrading so that it can be prevented from worsening. This paper reports on the geodetic monitoring of the Saint Vitus Cathedral and determines if the measured displacements were caused by temperature extensibility or by other influences.

\section{Description of the structure}

The layout of the Saint Vitus Cathedral is in the shape of a Greek cross, which consists of the nave and the transept. Along the nave is the space for the aisle with chapels to the side, which have lower ceilings than the main part of the nave. The walls between the 


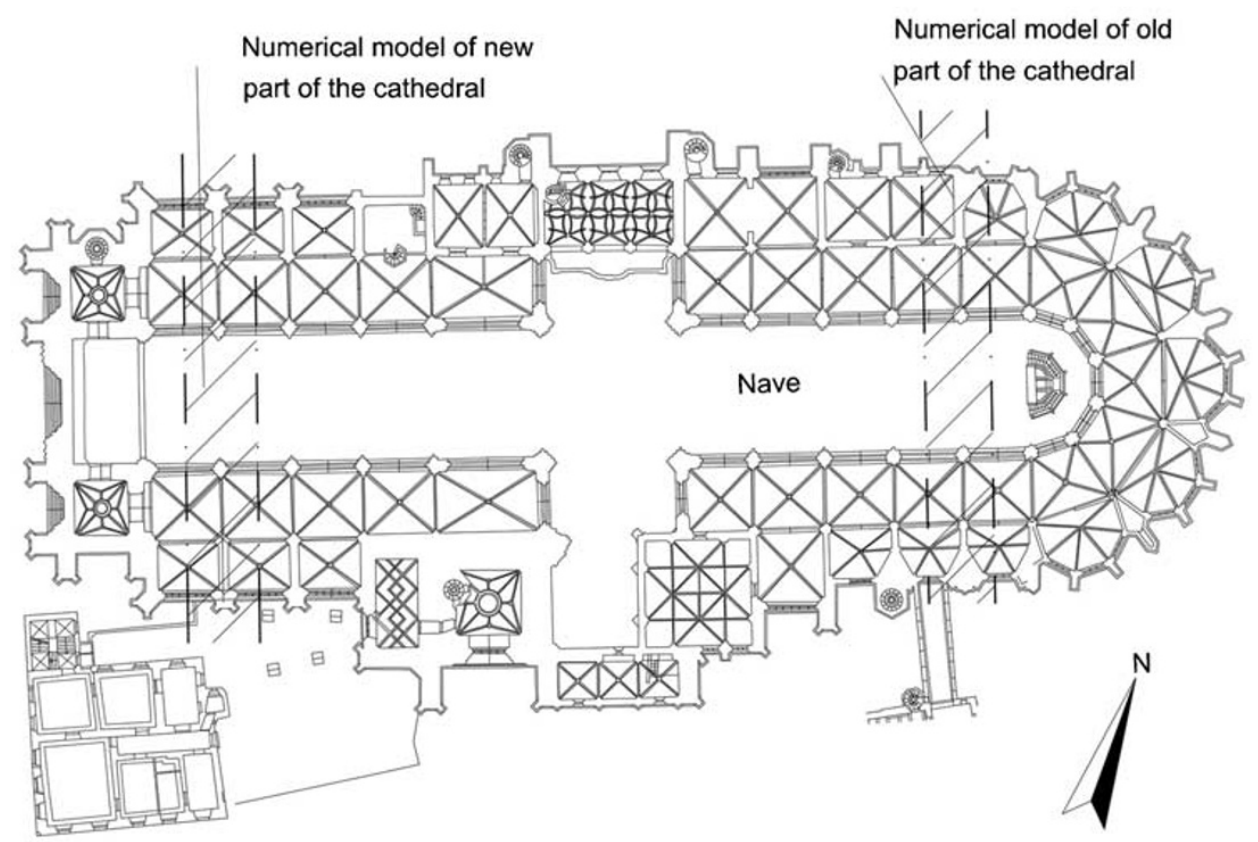

Figure I: Layout of the Saint Vitus Cathedral

chapels form the bases of the buttresses, which are connected (upper part) to the nave by flying buttresses. The load-bearing part of the structure is on the exterior of the building, and is therefore exposed to weather effects and other environmental and atmospheric influences. The Cathedral is constructed of sandstone and has been reinforced with steel rods.

\section{Geodetic measurement}

Geodetic monitoring commenced in several buildings of the Prague Castle in 2000, and this included both old and newer parts of the Saint Vitus Cathedral (Figure 1). Monitoring was conducted at four points in each cross-section, with the lower points situated approximately $2 \mathrm{~m}$ above the floor and upper points at approximately $17 \mathrm{~m}$ above the floor (Figure 2). Vertical and horizontal displacements were measured between these monitoring points throughout the year, usually in the evening when the Cathedral was closed to the public. Each measurement was compared with previous ones, and with those made initially on 10th July, 2000 to determine the degree of displacement (Procházka, 2003).

\section{NUMERICAL ANALYSIS}

The most precise analysis to determine the degree of displacement would utilise all available three-dimensional (3-D) elements, and would include the influences of heat transfer by convection and radiation, heat conduction, the influence of humidity on temperatures, changes in humidity, and temperature and humidity expansion. The computing time for such complex 3-D numerical analyses, however, would take weeks if not months using currently available computing technology. Therefore, to simplify the analyses, only the influence of heat transfer by convection was assumed and the other influences were neglected. 


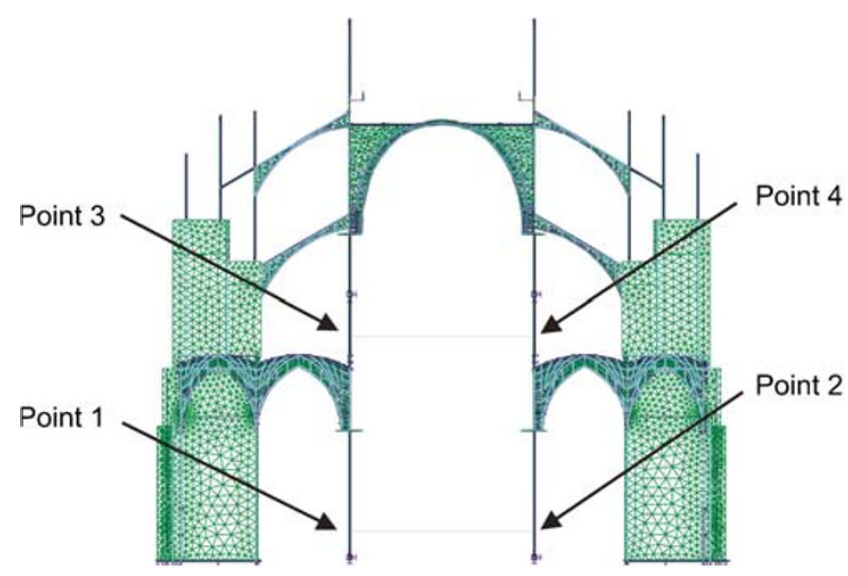

Figure 2: Cross-section of the new part of the cathedral with measured points

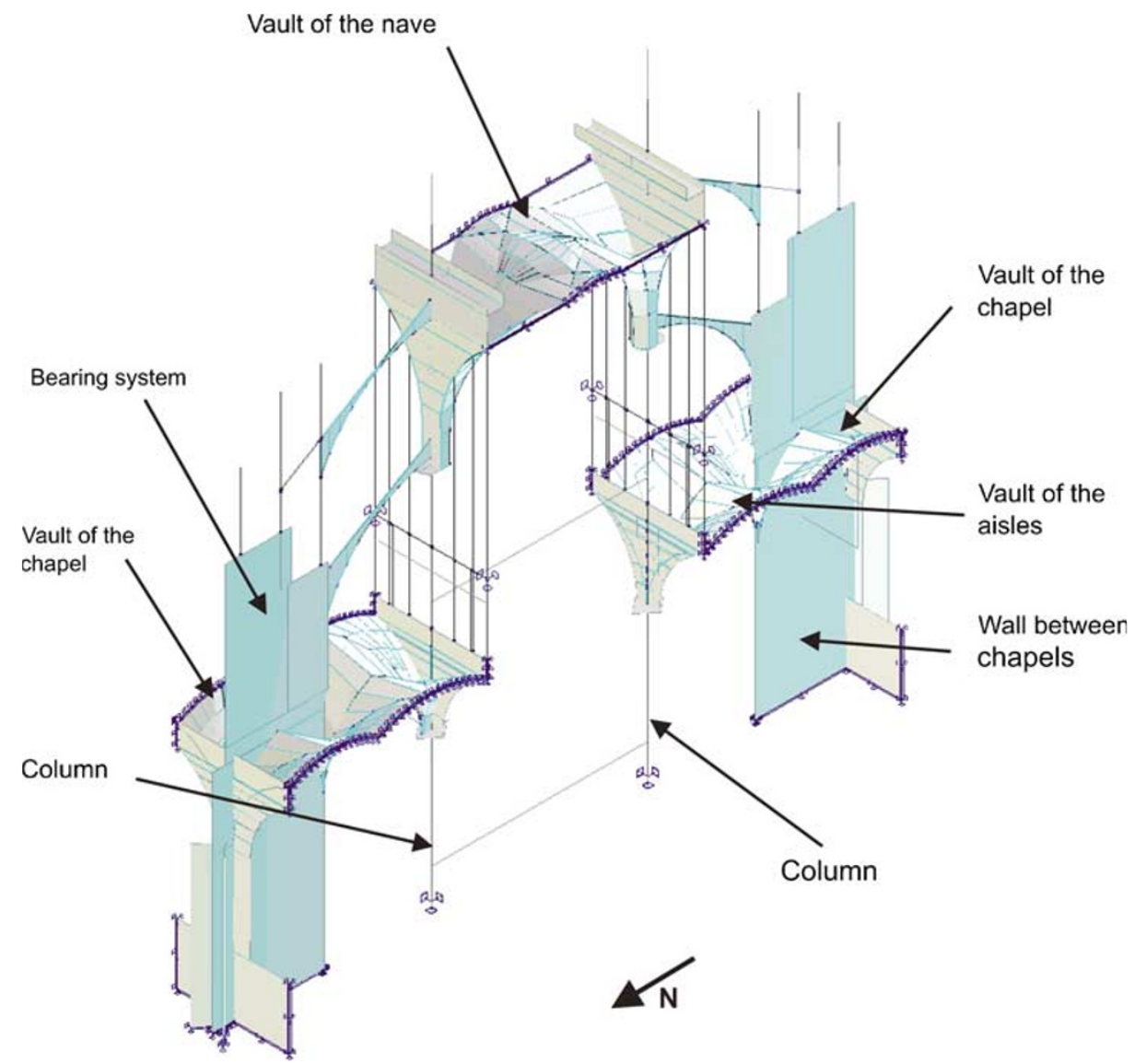

Figure 3: Numerical model of the new part of the structure of the cathedral

The Feat software (Scia Company, Czech Republic) was used to create a 3-D model, which consisted of 2-D elements (walls, vaults) and 1-D elements (columns, ribs of vaults) (Figure 3) while average temperatures were determined using the Adina Finite Element System (Adina R\&D Inc., MA, USA). Although the Adina System can also 
measure displacement, this was not done because of similar problems with computing time as described previously.

The following process was followed to determine the theoretical displacements for the structure:

1. Design of the numerical model using the Feat software.

2. Computation of the average temperature of the structure during geodetic measurement using the Adina System.

3. Comparison of the displacement acquired from the 3-D numerical model of the flying buttress of the bearing structure determined using the Adina System with the 2-D numerical model determined using the Feat software. This comparison was possible as these models cover only a small part of the overall structure and, therefore, the computing time was not a restricting factor.

4. Application of load to the numerical model (in Feat) by comparing the temperature differences between the measurements and the computation of displacement.

\section{Design of the numerical models using the Feat software}

Numerical models of the new and old parts of the Cathedral were designed; each included one bay, and all structures were modelled within each bay.

The model consisted of 2-D and 1-D elements. While the walls were modelled along their central plane for simplicity, the modelling of the vaults was more complicated and although these elements required simplification, the model still approximated reality almost exactly. The surfaces of the vaults were modelled as 12 areas that consisted of 2-D plane elements while the vault ribs were modelled as 12 linear beams that were in contact with the vault surface across their length.

At the foundation level, the model was supported at the restraint point. On the edge of the model (on the symmetry plane of the structure), the longitudinal displacement along the $Y$-axis and the rotations around the $X$-axis and $Z$-axis were prevented.

\section{Computation of the average temperatures of the structure}

Temperature analysis of the structure was mostly determined using 2-D models These models were used for straight and curved parts of the structure, which had constant crosssection dimensions or constant thickness. The models included the section of the structure which receives or gives off heat through its boundary. In these analyses, only the influence of heat transfer by convection was simulated. On the boundaries of the section, the boundary condition was defined by the coefficient of heat transfer at the air-sandstone interface and by the behaviour of the air temperature. The temperature of air had a defined continuance in time. The external air temperatures were obtained from the Prague hydrometeorological observatory while internal structural temperatures were modelled using the air temperature detected within the Cathedral.

Where cross-sections had different dimensions, it was necessary to adjust the time of analysis. The heat inertia of the most robust part of the structure was 3 weeks (the buttress of the bearing system with dimensions of $1.2 \times 5 \mathrm{~m}$ ) while the heat inertia of the thinner parts of the bearing system (the flying buttress with dimensions of $0.4 \times 1 \mathrm{~m}$ ) was $2-3$ days. The time length of one step was $1 \mathrm{~h}$.

The temperature fields of the three different parts of the bearing system analysed (Figure 4) are shown in Figure 5a-c. While in the flying buttress the highest temperature 


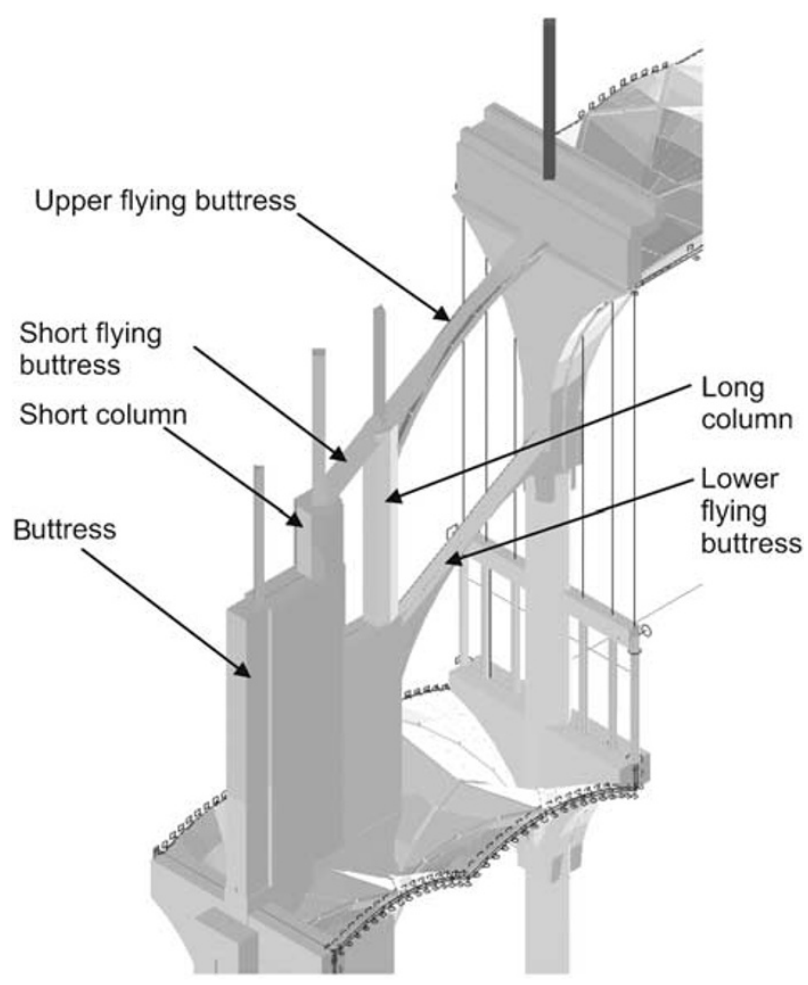

Figure 4: Bearing system of the cathedral

was at the edge of the section, the maximum temperature for the short column was in the centre and was due to the higher heat capacity of the short column following higher average daily temperatures in the week preceding measurement. The dimensions of short column cross-section were $1.2 \times 1.2 \mathrm{~m}$, whereas the width of the rectangular part of the section of the flying buttresses was $0.4 \mathrm{~m}$.

The comparison of temperature fields suggests that maximum and minimum temperatures inside the cross-sections were not very different. Temperature fluctuations during the day were reduced by the temperature inertia of the structure. Usually, only the surface layers of the structure reacted to daily temperature changes, and inside the structure the temperature approximated the mean value of the temperatures during the time of the monitoring.

Comparing the deformations gained from the 3-D numerical model of the flying buttress of the bearing system using the Adina system and with the 2-D model using the Feat software

The 3-D numerical model of the lower flying buttress was designed using the Adina system (Figure 6a and b). The numerical model in Feat used the average temperature of the structure, which was computed from the temperatures in the nodes of the mesh in the 3-D model in Adina.

Reasons for using the 3-D model:

- Changes in the cross-section of the structure lengthwise.

- Verification of the applicability of the 2-D model and its comparison with the 3-D model. 


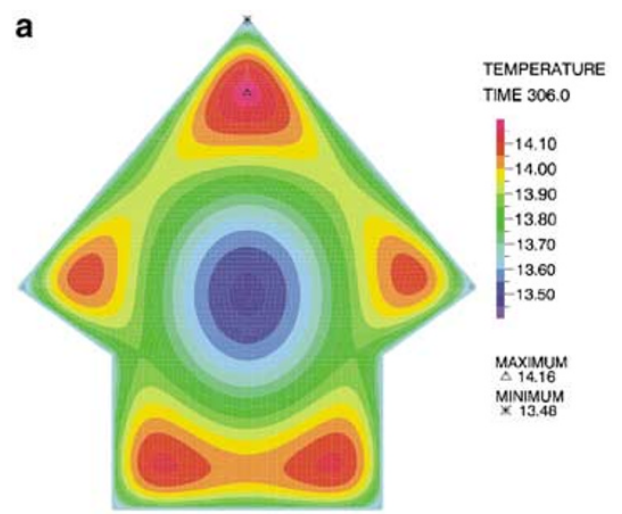

C

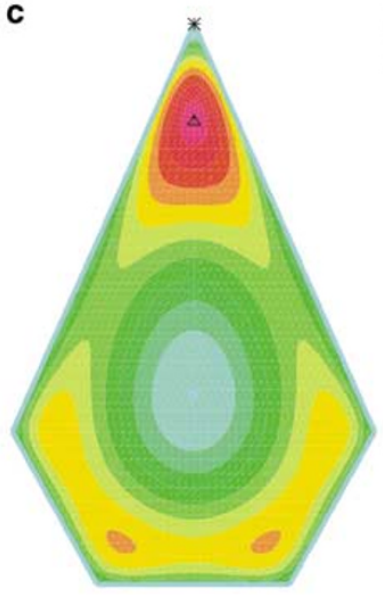

b

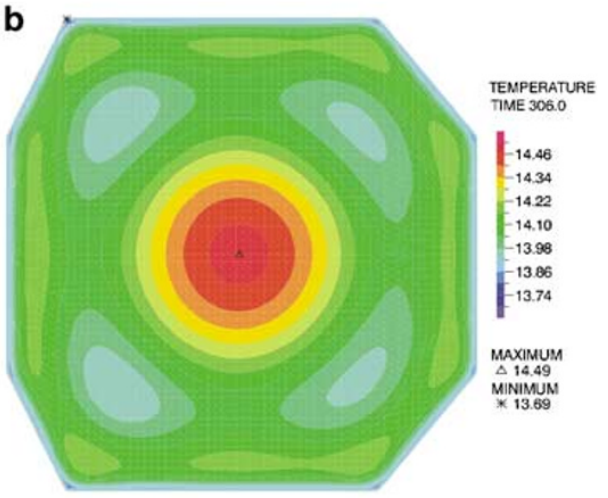

TEMPERATURE TIME 306.0

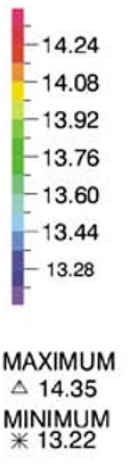

Figure 5: Temperatures in the (a) lower flying buttress, (b) short column and (c) short flying buttress of the bearing system (determined using the Adina System)

Three different periods were compared and it was found out that the results obtained from the 2-D and the 3-D models were almost the same. Another benefit of the 3-D model was the fact that the lower flying buttress was stretching and bending like a stiff unit that was distorted mainly by the differences of the average temperatures of the structure. This situation was caused by the simplification of the model, which only assumed the influence of heat transfer by conduction and the same boundary conditions on all surfaces of the structure.

\section{Loading of the numerical model in the program Feat}

To determine the theoretical displacements caused by temperature expansion, it was necessary to load the numerical model in the structures with the temperature differences that occurred during the time between the geodetic measurements (Figure 7). To analyse the temperature differences, three variants were chosen.

In the first variant, the temperature of the structure was the same as the temperature of the air checked during the geodetic measurement. The temperatures of the air inside and outside the Cathedral were measured. In this variant, heat inertia of the structures was not assumed. The second variant was more exact and came from the hypothesis that massive brick structures have high heat inertia, and so it was assumed that the average temperature of the outside structure approximated the average external air temperature over the 
a
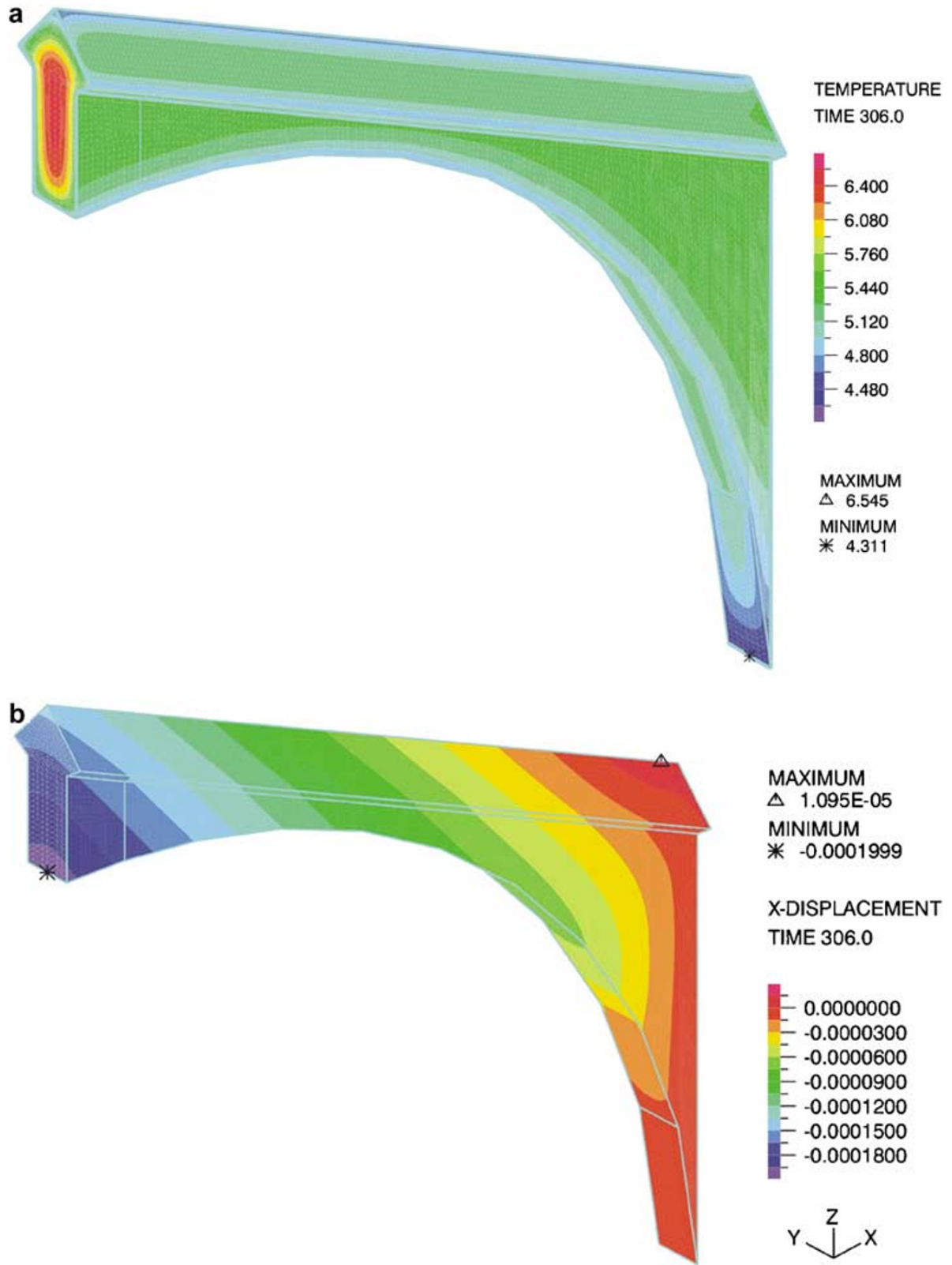

Figure 6: 3-D models of (a) the temperatures inside and (b) the displacement of, the flying buttress determined using the Adina system

preceding week before geodetic measurement was performed. This assumption did not take into account the different heat capacities of the external structures. For the inside structures, the same assumption was chosen as in the first variant.

The third variant aimed to find the average temperatures more exactly. The temperatures were obtained from the numerical analysis of all parts of the structure using the Adina system.

The three variants were examined because the results of the first variant were not convincing enough, and the accuracy of the approach grew with each variant. 


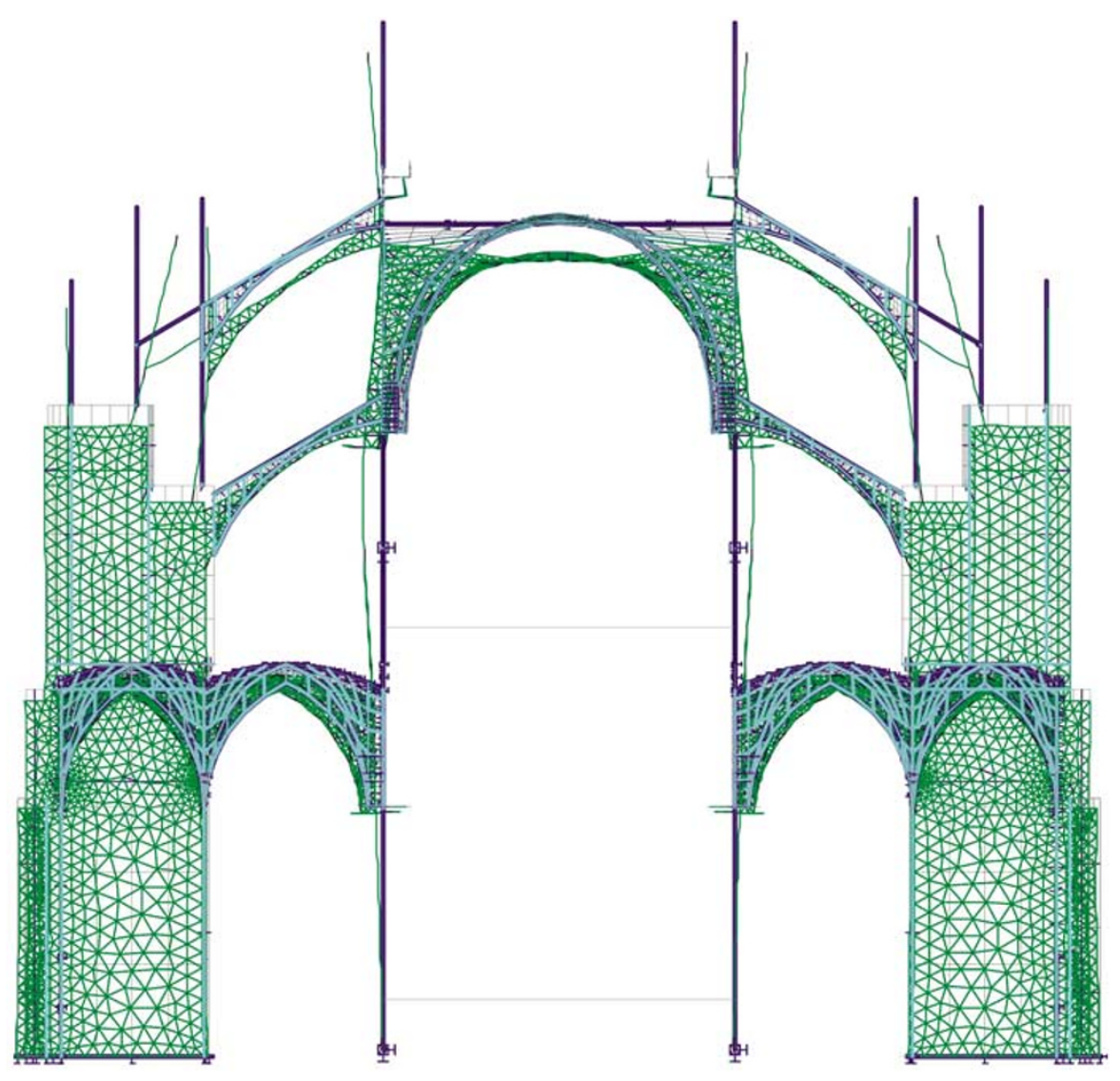

Figure 7: Total displacements - numerical model in Feat

\section{COMPARISON OF THE THEORETICAL RESULTS WITH THE GEODETIC MEASUREMENT AND DISCUSSION}

The values gained from the numerical model were compared with the results of the geodetic measurements. These were the values of the relative displacements between a pair of points on the northern or southern side of the Cathedral in two sections, which corresponded to the sections analysed in the numerical models created in the programme Feat. Three variants of loading were counted. To check the differences between the results globally, the mean-root-square error was counted (Table 1).

The differences between the variants of loading were small (less than 10 per cent) for the vertical displacements at the measured points. This was because the deformations of the columns of the nave were mainly influenced by the temperature of the air inside the Cathedral. During the measurement, the inside temperature did not differ too much from the internal temperatures of the structures of the Cathedral. The second reason could be the fact that the structures connected with the column only partially influenced the deformations of the column of the nave. This influence was small because of the following reasons:

- The outside structures also changed their vertical dimensions because of the change in external temperature, but the temperature differences of the outside structures were not markedly different from those inside the Cathedral. The maximum difference that influenced the vertical dilatation of the columns of the nave was $7^{\circ} \mathrm{C}$, but were mostly existed in the range of $1-3^{\circ} \mathrm{C}$. 
Table I: Mean-root square error — horizontal and vertical displacement

\begin{tabular}{|c|c|c|c|c|c|c|c|c|}
\hline & \multicolumn{4}{|c|}{ Horizontal displacement } & \multicolumn{4}{|c|}{ Vertical displacement } \\
\hline & \multicolumn{2}{|c|}{$\begin{array}{l}\text { Model of section of } \\
\text { old part of Cathedral }\end{array}$} & \multicolumn{2}{|c|}{$\begin{array}{l}\text { Model of section of } \\
\text { new part of Cathedral }\end{array}$} & \multicolumn{2}{|c|}{$\begin{array}{l}\text { Model of section of } \\
\text { old part of Cathedral }\end{array}$} & \multicolumn{2}{|c|}{$\begin{array}{l}\text { Model of section of } \\
\text { new part of Cathedral }\end{array}$} \\
\hline & North & South & North & South & North & South & North & South \\
\hline First variant & 0.719 & 0.42 & 0.762 & 0.417 & 0.693 & 0.443 & 0.451 & 0.563 \\
\hline Second variant & $0.45 I$ & 0.338 & 0.581 & 0.273 & 0.691 & 0.467 & 0.457 & 0.577 \\
\hline Third variant & 0.499 & 0.218 & 0.459 & 0.207 & 0.725 & 0.443 & 0.454 & 0.519 \\
\hline
\end{tabular}

- The second and more important reason was that the column of the nave was connected with the bearing system by the flying buttresses. They behaved like the beams loaded by bending. The bending resistance of the flying buttresses was markedly lower than the stiffness of the column in tension or pressure. This is the reason why the difference of the extension of the buttress of the bearing system and the column of the nave was small.

The situation was completely different for horizontal displacements. The best results were admittedly acquired from the third variant of the loading of the numerical model. The values of the mean-root-square errors of both models were close to the accuracy of the geodetic measurement on the southern part of the Cathedral. This finding could seem paradoxical, because the southern part of the Cathedral was exposed to the most solar radiation. One of the reasons could be the fact that solar radiation eliminated the influence of humidity. The heat obtained from the sun was partially consumed to evaporate water from porous sandstone.

The situation on the northern part of the Cathedral was worse. In the third variant, the mean-root-square error on the northern part was more than twice as large as the one on the southern part. This fact could be caused by the following reasons:

- On the northern side of the Cathedral, the temperature differences were markedly different from the ones obtained from the observatory.

- The northern side of the Cathedral was not exposed to solar radiation and the time that was needed to dry the structure after rain was longer. Therefore, the effects of increased humidity that increased could have caused deformations in the structure.

- Snow cover, which could have influence on the temperature or the humidity of the structure, would last longer on the northern side of the Cathedral.

- The northern column of the nave was exposed to solar radiation and could therefore bend. The bending was caused by the unequal heating of the southern part in comparison with the northern part. As the column was situated in the interior, incident solar radiation entered through the window and therefore, its intensity was lower than in the exterior. Another influence reducing the intensity of incident solar radiation was partial shading of the windows by the bearing system.

\section{APPLICABILITY OF THE ANALYSIS TOOL TO OTHER TYPES OF BUILDINGS IN DIFFERENT CLIMATIC CONDITIONS}

The bearing system, which is situated in the exterior, exercises a dominant influence on the deformations of the columns of the nave. Some interior structures also, however, eminently influence the deformation of the columns - especially the vault of the aisle. 
The Saint Vitus Cathedral is located in Prague, where the climate is moderate. During the years 2000-2004, the average daily temperatures ranged from -17 to $28^{\circ} \mathrm{C}$. Besides, the average daily temperatures may also fluctuate by $20^{\circ} \mathrm{C}$ during the month. The distribution of the precipitation is almost uniform during the year, and dry seasons of various lengths are superseded by humid seasons.

This analysis is also applicable to other buildings made of concrete and masonry, but not to steel structures. These are usually more slender than those built of concrete or masonry, and their heat capacity is lower. Therefore, they can be heated by solar radiation more easily. This is the reason why the influence of solar radiation has to be covered for steel structures exposed to the sun. This fact also applies to very slender structures made of concrete and masonry.

The volume changes caused by the fluctuation of moisture are long-standing. That is why this influence could be stronger in the climates where very dry seasons are superseded by seasons of rainfall. This is the reason why the influence of moisture extensibility should be involved in this climatic condition. Porous materials like brick masonry, concrete and sandstone change their volume also because of the fluctuation of the moisture.

In general, this analysis is applicable not only to historical cathedrals, but also to other buildings. Naturally, it is necessary to respect the specifics of the structure and climate and also include the other effects described above.

\section{CONCLUSION}

The comparison of the results gained from the numerical modelling and from geodetic measurement has confirmed that the structure of the Cathedral is deformed mainly due to the influence of temperature variations. This finding is correct for the southern side of the Cathedral while the situation is more complicated on the northern side. The results of the numerical model varied more compared to those of the geodetic measurements. This could have been caused by the influence of humidity variations of the structure, which were not included in the model.

The structure is loaded by the cyclic temperature variations that may have a fatigue character. The geodetic measurement and its confrontation with the numerical model have not proved any degradation process.

This research is still continuing and will cover the influence of sun radiation and humidity.

\section{Acknowledgments}

We acknowledge the support of the Czech Science Foundation for funding the projects 'Design reliability of concrete frames under earthquakes' and 'Stability of historical buildings and monuments' and the support of the Ministry of Education for funding the project 'Algorithms for computer simulation and application in engineering'.

\section{Reference}

Procházka, J. (2003) 'Displacements and deformation measurement of historical buildings with geodetical methods', Stavební obzor: Civil Engineering Journal, 8, 232-238. 